\title{
PERAN GURU PENDIDIKAN KEWARGANEGARAAN DALAM PENERAPAN ETIKA DAN MORAL PESERTA DIDIK DALAM LINGKUNGAN FORMAL DI SMK NEGERI 1 STABAT TAHUN PELAJARAN 2018/2019
}

\author{
Retno Anggraini $^{1}$, Surya Wibawa ${ }^{2}$
}

\begin{abstract}
ABSTRAK
Peran Guru PKn dalam penerapan etika dan moral bukan hanya mengajar tetapi juga mendidik peserta didik agar menjadi manusia yang lebih baik, baik dalam beretika dan bermoral, sehingga dapat mendisiplinkan peserta didik agar peserta didik menjadi patuh terhadap aturan-aturan sekolah dan norma-norma hidup dalam keluarga, masyarakat, bangsa dan negara. Etika adalah cabang ilmu yang membicarakan tingkah laku atau perbuatan manusia dalam hubungannya dengan yang baik buruk. Moral merupakan pengetahuan yang menyangkut budi pekerti manusia yang beradab. Moral juga berarti ajaran yang baik dan buruk perbuatan dan kelakuan (akhlak). Penelitian dilakukan dengan cara observasi, wawancara dan dokumentasi data tenaga pengajar di SMK Negeri 1 Stabat. Penelitian ini dilakukan disekolah tersebut melalui wawancara dengan Kepala Sekolah SMK Negeri 1 Stabat dan 2 (dua) guru mata pelajaran PKn serta wawancara dengan 4 (empat) orang siswa. Dari semua observasi dan wawancara yang dilakukan maka dapat dihasilkan bahwa peranan guru PKn dalam penerapan etika dan moral di SMK Negeri 1 Stabat mempunyai peran yang cukup penting.
\end{abstract}

Kata Kunci : Peran Guru PKn, Etika dan Moral

\section{BAB I. PENDAHULUAN}

\section{A. Latar Belakang Masalah}

Pendidikan bertujuan bukan hanya membentuk manusia yang cerdas otaknya dan trampil dalam melaksanakan tugas, namun diharapkan menghasilkan manusia yang memiliki moral, sehingga menghasilkan warga negara yang baik. Moral merupakan pengetahuan yang menyangkut budi pekerti manusia yang beradab.

Moral juga berarti ajaran yang baik dan buruk perbuatan dan kelakuan (akhlak). Salah satu hal yang cukup mencolok sebagai perbedaan moral dan etika adalah kecenderungan konflik yang bisa dimunculkan oleh 2 hukum ini. Moral merupakan nilai dalam masyarakat yang secara otomatis akan diikuti oleh beberapa etika dalam proses pengaplikasiannya. Adanya moral maka otomatis ada etika pula. Seperti moral menghormati orang yang lebih tua, dengan etikanya yaitu berkata lemah lembut, tidak membantah dan penuh sikap hormat.

Sumber daya manusia merupakan aspek utama dalam pembangunan suatu bangsa. Salah satu sumber daya manusia yang dianggap penting yaitu generasi muda. Peran generasi muda tergolong sangat penting dalam rangka pembangunan di Indonesia sebagai sebuah negara yang merdeka. Generasi muda diharapkan mampu bersikap nasionalis sesuai dengan Pancasila dan UUD 1945 dan bermoral sesuai dengan ajaran agama.

Pendidikan adalah suatu proses yang berlangsung sejak seseorang masih kecil untuk mencapai kematangan berpikir atau kedewasaan. Pendidikan merupakan hal yang tidak dapat dilepaskan dari kehidupan manusia. Pendidikan tidak lain sebagai proses perolehan pengetahuan, sikap, kepercayaan, dan aspek perilaku lainnya kepada setiap generasi. 
Sekolah sebagai lembaga formal pelaksanaan pendidikan merupakan pemegang peran utama peyaluran ilmu kepada siswa. Sekolah merupakan salah satu pusat pendidikan yang diharapkan bisa mencerdaskan kehidupan bangsa dan mengembangkan manusia menjadi manusia beriman dan berguna bagi bangsa dan negaranya.

Salah satu fungsi sekolah yaitu bertanggung jawab melaksanakan pembinaan menurut ketentuan yang berlaku. Pendidikan moral adalah pendidikan untuk menjadikan anak manusia bermoral atau bermanusiawi. Artinya pendidikan moral adalah pendidikan yang bukan mengajarkan tentang akademik, namun non akademik khususnya tentang sikap dan bagaimana perilaku sehari-hari yang baik.

Tugas sekolah dan guru benar-benar akan sangat diuji untuk dapat menyelesaikan masalah etika dan moral siswa dan akan sangat memprihatinkan ketika nasihat, teguran ataupun hukuman yang diberikan kepada siswa untuk mengubah perilakunya malah kemudian menjadi bumerang kepada guru yang sebenarnya hanya bermaksud untuk menjalankan tugasnya dan membantu siswa menjadi orang yang lebih baik. Berdasarkan Latar Belakang penelitian ini dirumuskan masalah sebagai berikut :

1. Bagaimana penerapan etika dan moral dalam lingkungan formal disekolah melalui pendidikan kewarganegaraan?

2. Bagaimana pengembangan etika dan moral dalam lingkungan formal disekolah melalui pendidikan kewarganegaraan?

3. Bagaimana peran etika pendidikan dalam lingkungan formal disekolah melalui pendidikan kewarganegaraan?

\section{KAJIAN PUSTAKA}

Kata "etika" berasal dari bahasa Yunani kuno, ethos. Dalam bentuk tunggal kata ethos memiliki beberapa makna: tempat tinggal yang biasa, padang rumput, kandang; kebiasaan, adat; akhlak, watak; perasaan, sikap, cara berpikir. Sedang bentuk jamak dari ethos, yaitu ta etha, berarti adat kebiasaan. Dalam arti terakhir inilah terbentuknya istilah "etika" yang oleh Aristoteles, seorang filsuf besar Yunani kuno (381-322 SM), dipakai untuk menunjukkan filsafat moral. Karena itu, dalam arti yang terbatas etika kemudian berarti ilmu tentang apa yang biasa dilakukan atau ilmu tentang adat kebiasaan.

Etika pada hakikatnya mengamati realitas moral secara kritis, dan dalam kajian secara terminologi etika berarti sebuah cabang ilmu yang membicarakan perbuatan/tingkah laku manusia dalam hubungannya dengan yang baik dan yang buruk. Surajiyo mengatakan, "Secara terminologi, etika adalah cabang ilmu yang membicarakan tingkah laku atau perbuatan manusia dalam hubungannya dengan yang baik buruk. Yang dapat dinilai baik buruk adalah sikap manusia, yaitu yang menyangkut perbuatan, tingkah laku, gerakan, kata-kata, dan sebagainya".

Kata moral selalu mengarah kepada baik buruknya perbuatan manusia. Inti pembicaraan tentang moral adalah menyangkut bidang kehidupan manusia dinilai dari baik atau buruk perbutaannya. Fungsi mengajar dalam paradigma pembelajaran tidak sekedar memberi atau menyampaikan pelajaran kepada peserta didik, tetapi juga terkandung makna adanya proses perubahan tingkah laku peserta didik sesuai dengan tujuan yang direncanakan. Atas dasar ini, Wina Sanjaya menegaskan bahwa istilah pembelajaran menunjuk pada usaha peserta didik mempelajari bahan ajar sebagai akibat perlakuan guru. Proses pembelajaran yang dilakukan peserta didik di sini tidak mungkin terjadi tanpa perlakuan guru. Yang berbeda dalam proses pembelajaran ini adalah peran keduanya.

Pendidikan Kewarganegaraan menurut Zamroni adalah pendidikan demokrasi yang bertujuan untuk mempersiapkan warga 
masyarakat berpikir kritis dan bertindak demokratis, melalui aktiftas menanamkan kesadaran kepada generasi baru bahwa demokrasi adalah bentuk kehidupan masyarakat yang paling menjamin hak-hak warga masyarakat.

Terkait dengan karakter siswa, guru juga menjadi figur sentral yang mempengaruhinya dalam melakukan proses pembelajaran yang berkarakter. Bahkan di sekolah atau lembaga pendidikan lain yang masih terbatas sarana dan prasarananya, gurulah yang menjadi ujung tombak keberhasilan proses pembelajaran. Guru berperan sebagai sumber ilmu atau sumber belajar bagi siswanya. Siswa akan belajar dari apa yang diberikan oleh gurunya.

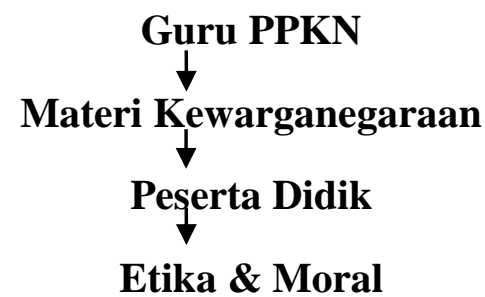

Kerangk Berpikir

\section{METODOLOGI PENELITIAN}

Jenis penelitian ini adalah penelitian kualitatif dengan menggunakan analisis deskriptif yaitu penelitian yang dilakukan untuk memperoleh gambaran situasi dan kejadian-kejadian secara kongkret tentang keadaan obyek atau masalah.

Penelitian ini dilaksanakan di SMK Negeri 1 Stabat yang terletak di Jalan K.H. Wahid Hasyim Kecamatan Stabat. Penelitian ini akan dilaksanakan pada semester ganjil tahun pelajaran 2017/2018.

Dalam penelitian ini yang dijadikan sebagai subjek adalah siswa SMK Negeri 1 Stabat Kabupaten Langkat, sementara yang menjadi objek dari penelitian ini ialah peningkatan etika dan moral.

\section{Teknik Pengumpulan Data}

1. Observasi

Teknik pengamatan atau observasi dapat dilakukan terhadap objek, baik secara langsung maupun tidak langsung.

2. Wawancara

Wawancara merupakan salah satu teknik pengumpulan data yang dilakukan dengan cara melakukan tanya jawab, baik secara langsung dan tidak langsung dengan sumber data..

3. Dokumentasi

Teknik dokumentasi merupakan suatu pemgambilan data yang diperoleh dari informasi-informasi dan dokumendokumen yang digunakan untuk mendukung keterangan-keterangan tentang sesuatu yang diteliti.

\section{Analisis Data}

Analisis data berlangsung bersamaan dengan proses pengumpulan data. Diantaranya yaitu reduksi data, penyajian data dan simpulan/verifikasi. Namun ketiga tahapan tersebut berlangsung secara simultan.

1. Reduksi Data

Reduksi data merupakan kegiatan mencatat atau menelaah kembali seluruh catatan lapangan yang diperoleh dari hasil observasi, wawancara, studi dokumentasi dalam bentuk uraian atau laporan yang rinci.

2. Penyajian Data (Data Display) Alur penting dari kegiatan analisis data adalah penyajian data yang membatasi pada suatu penyajian sebagai sekumpulan informasi tersusun yang memberi kemungkinan adanya penarikan kesimpulan dan pengambilan keputusan.

3. Menarik Kesimpulan/Verifikasi Menurut Miles dan Huberman menyatakan "langkah ketiga dalam 
analisis data kualitatif adalah penarikan kesimpulan dan verifikasi”.

\section{Desain Penelitian}

Penelitian ini menggunakan jenis penelitian kualitatif deskriptif yang artinya penelitian ini berusaha mendeskripsikan suatu gejala, peristiwa, dan kejadian saat sekarang dengan maksud memperoleh data yang berbentuk kata, kalimat, skema, dan gambar.

\section{HASIL PEMBAHASAN}

\section{A. Temuan Umum}

\section{Sejarah berdirinya SMK Negeri}

SMK Negeri 1 merupakan sekolah yang terletak dikota Stabat yang beralamat di jalan K.H Wahid Hasyim Stabat. SMK Negeri 1 Stabat ini banyak diminati karena letaknya yang strategis dan juga keadaan sekolah yang cukup nyaman.

\section{Visi dan Misi SMK Negeri 1 Stabat \\ Visi}

SMK Negeri 1 Stabat merupakan lembaga yang unggul dalam menyelenggarakan pendidikan pelatihan siswa dalam menghasilkan tenaga yang profesionaldan memiliki kompetensi standart nasional/internasional yang mampu bersaing pada era pasar global.

\section{Misi}

Meningkatkan komitmen dan keunggulan tamatan yang terampil dalam kompotensi standart nasional/internasional melalui :

1. Pengembangan dan penyelenggaraan diklat kompetensi yang sesuai dengan kebutuhan pasar nasional/internasional serta mengacu pada competency based training (CBT)

2. Pemberdayaan dan peningkatan kualitas kependidikan fasilitas dan sumber daya lingkungan yang sesuai dengan criteria standart nasional/internasional.
3. Pengembangan dan implementasi manajemen kualitas yang mengacu pada standart manajemen iso 9001.

4. Penetaan lingkungan belajar yang kondusif dan mendukung kegiatan pembelajaran yang efektif dan efesien mewujudkan kometensi tamatan yang mampu bersaing pada pasar nasional/internasional.

5. Peningkatan kerja sama yang lebih erat dengan lemdiklat atau DU/DI yang memiliki reputasi tingkat nasional atau pu internasional.

\section{Tugas dan Tanggung jawab Sekolah}

SMK Negeri 1 Stabat merupakan unit pelaksanaan teknik (UPT) lembaga pendidikan jalur sekolah secara garis besarnya memiliki tugas serta tanggung jawab sebagai berikut :

a. SMK Negeri 1 Stabat merupakan pelaksanaan pendidikan dan pengajar sesuai dengan kurikulumnya yang berlaku

b. SMK Negeri 1 Stabat melaksanakan pendidikan sekolah selama jangka waktu tertentu sesuai dengan jenis, sifat dan jenjang sekolah

c. SMK Negeri 1 Stabat membina siswa/i melalui wadah organisasi sekolah (OSIS)

d. SMK Negeri 1 Stabat melaksanakan urusan tata usaha

e. SMK Negeri 1 Stabat menjalin kerjasama dengan orang tua, masyarakat dan instansi-instansi terkait dalam penyelenggaraan pendidikan

f. SMK Negeri 1 Stabat bertanggung jawab sepenuhnya atas keberhasilan dan kelancara dalam penyelenggaraan pendidikan sekolah

g. Segala pertanggung jawaban SMK Negeri 1 Stabat disampaikan kepada Dinas Pendidikan Kabupaten Langkat dan Provinsi

h. SMK Negeri 1 Stabat melaksanakan bimbingan dan konseling di sekolah.

\section{Sarana dan Prasarana}

Tabel . Sarana fasilitas SMK Negeri 1 Stabat 


\begin{tabular}{llcc}
\hline No & Jenis sarana & Jumlah & Keadaan \\
\hline 1 & Ruang Kepsek & 1 & Baik \\
\hline 2 & Ruang Guru & 1 & Baik \\
\hline 3 & Ruang Tata Usaha & 1 & Baik \\
\hline 4 & Ruang BK & 1 & Baik \\
\hline 5 & Ruang Belajar & 52 & Baik \\
\hline 6 & Ruang UKS & 1 & Baik \\
\hline 7 & $\begin{array}{l}\text { Ruang Agama } \\
\text { Kristen }\end{array}$ & 1 & Baik \\
\hline 8 & $\begin{array}{l}\text { Ruang Tata } \\
\text { Busaha Butik }\end{array}$ & 4 & Baik \\
\hline 9 & Ruang Bengkel & 4 & Baik \\
\hline 10 & Perpustakaan & 1 & Baik \\
\hline 11 & Lab. Komputer & 1 & Baik \\
\hline 12 & Lab. Bahasa & 1 & Baik \\
\hline 13 & Masjid & 1 & Baik \\
\hline 14 & Kamar Mandi & 13 & Baik \\
\hline 15 & Pos Satpam & 1 & Baik \\
\hline 16 & Parkir & 2 & Baik \\
\hline 17 & $\begin{array}{l}\text { Rumah Penjaga } \\
\text { Sekolah }\end{array}$ & 1 & Baik \\
\hline & & & \\
\hline
\end{tabular}

\section{Keadaan Fisik Sekolah}

A. Keadaan Fisik Sekolah

1. Luas tanah : $51.510 \mathrm{~m}^{2}$

2. Jumlah ruang kelas : 52 ruangan

3. Ukuran ruang kelas : $72 \mathrm{~m}^{2}$

B. Keadaan Lingkungan Sekolah

1. Jenis bangunan yang mengelilingi sekolah :
a. Gedung serba guna stabat
b. Perkantoran Pemda
c. Dinas Pertahanan
d. Kebun Tebu

2. Kondisi lingkungan sekolah :
a. Baik
b. Bersih
c. Nyaman

C. Fasilitas Sekolah
1. Perpustakaan : Baik
2. Laboratorium : Baik
3. Ruang BP : Baik
4. Ruang kesenian : Baik
5. Ruang tata usaha : Baik
6. Masjid : Baik

D. Guru dan Siswa

1. Jumlah Guru :120 Orang

2. Jumlah Siswa Perkelas : 35 siswa
3. Jumlah Siswa Seluruhnya : 1.575 siswa.

\section{Keadaan Tenaga Pendidik SMK Negeri 1 Stabat}

Adapun tenaga pendidik SMK Negeri 1 Stabat sebagai berikut :

Tabel . Jumlah Tenaga Pengajar SMK Negeri 1 Stabat

\begin{tabular}{ccccc}
\hline No & $\begin{array}{c}\text { Tenaga } \\
\text { Pendidik }\end{array}$ & \multicolumn{2}{c}{$\begin{array}{c}\text { Jenis } \\
\text { Kelamin }\end{array}$} & Posisi \\
\cline { 2 - 4 } & & $\mathbf{L}$ & $\mathbf{P}$ & \\
\hline 1 & 1 & 1 & - & $\begin{array}{c}\text { Kepala } \\
\text { Sekolah }\end{array}$ \\
\hline 2 & 1 & - & - & $\begin{array}{c}\text { Wakil } \\
\text { Kepala } \\
\end{array}$ \\
& & & & \begin{tabular}{c} 
Sekolah \\
\hline 3
\end{tabular} \\
\hline 4 & 2 & 1 & - & PKS \\
\hline Jumlah & 120 & 61 & 55 & Guru \\
\hline & 124 & 63 & 55 & \\
\hline
\end{tabular}

Tabel diatas menunjukkan bahwa tenaga pengajar (guru) berjumlah 120 orang.

Tabel . Jumlah Tenaga Pegawai SMK Negeri 1 Stabat

\begin{tabular}{ccccc}
\hline No & $\begin{array}{c}\text { Pegaw } \\
\text { ai }\end{array}$ & \multicolumn{2}{c}{$\begin{array}{c}\text { Jenis } \\
\text { Kelamin }\end{array}$} & Jabatan \\
\cline { 3 - 4 } & 1 & 1 & - & $\begin{array}{c}\text { Kepala Tata } \\
\text { Usaha }\end{array}$ \\
\hline 1 & 4 & 1 & 3 & $\begin{array}{c}\text { Staf Tata } \\
\text { Usaha }\end{array}$ \\
\hline 2 & 4 & 2 & 3 & \\
\hline Jumlah & 5 & & & \\
\hline
\end{tabular}

Tabel diatas menunjukkan bahwa jumlah pegawai di SMK Negeri 1 Stabat sebayak 5 orang terdiri dari 1 orang kepala tata usaha dan 4 orang staf tata usaha

Tabel. Jumlah Guru PKn di SMK Negeri 1

\begin{tabular}{|c|c|c|c|c|}
\hline $\begin{array}{l}\mathbf{N} \\
\text { a }\end{array}$ & $\begin{array}{l}\text { Nama } \\
\text { Guru }\end{array}$ & $\begin{array}{l}\text { Mengasuh } \\
\text { Kelas }\end{array}$ & $\begin{array}{l}\text { Pendidi } \\
\text { kan }\end{array}$ & $\begin{array}{l}\text { Jumla } \\
\text { h } \\
\text { Siswa } \\
\text { Asuh }\end{array}$ \\
\hline 1 & $\begin{array}{c}\text { Drs. Aman } \\
\text { Tampubol } \\
\text { on }\end{array}$ & $\begin{array}{l}\mathrm{X} \mathrm{BB}^{1 \mathrm{dan} 2} \text {, } \\
\mathrm{AK}, \mathrm{PM}, \mathrm{XI} \\
\mathrm{AK}, \mathrm{BB}^{1} \text { dan }\end{array}$ & $\begin{array}{c}\text { S-1 } \\
\text { PPKn }\end{array}$ & 385 \\
\hline
\end{tabular}




\begin{tabular}{|c|c|c|c|c|}
\hline & & $\begin{array}{l}\text { XII BB }{ }^{1 \text { dan } 2}, \\
\text { AK, ADP, PM }\end{array}$ & & \\
\hline 2 & $\begin{array}{l}\text { Wagimin, } \\
\text { S, Pd }\end{array}$ & $\begin{array}{l}\text { X DPIB }^{1 \text { dan } 2}, \\
\text { XI DPIB }^{2} \text { dan } \\
\text { XII TLI }^{1 \text { dan } 2,} \\
\text { AP }^{1 \text { dan } 2} \\
\text { DPIB }^{1 \text { dan } 2}, \\
\text { TKR }^{1,2 \text { dan } 3}\end{array}$ & $\begin{array}{c}\text { S-1 } \\
\text { PPKn }\end{array}$ & 420 \\
\hline
\end{tabular}

Dari tabel diatas, dapat diketahui bahwa jumlah guru mata pelajaran PKn di SMK Negeri 1 Stabat berjumlah 2(dua) diketahui bahwa semua guru mata pelajaran PKn merupakan lulusan (S-1) PPKn.

\section{B. Temuan Khusus}

1. Wawancara dengan Kepala Sekolah SMK Negeri 1 Stabat

2. Wawancara dengan guru mata pelajaran pkn oleh bapak wagimin, s.pd dan bapak dr. Aman tampubolon

3. Wawancara dengan siswa/i SMK Negeri 1 Stabat.

Dari semua wawancara yang dilakukan dapat diambil kesimpulan bahwa peran guru pendidikan kewarganegaraan dalam penerapan etika dan moral peserta didik dalam lingkungan formal di SMK Negeri 1 Stabat sudah baik dan sudah dilaksanakan oleh guru mata pelajaran PKn. Dengan adanya motivasi dan arah-arahan yang diberikan oleh guru mata pelajaran PKn maka kedisiplinan siswa dapat dibentuk dari keteladanan guru dan juga dari setiap diri masing-masing siswa, disini terlihat bahwa guru mata pelajaran PKn sudah menerapkan beberapa strategi agar siswanya menjadi disiplin.

\section{Pembahasan Hasil Penelitian}

Penelitian ini menyajikan dan memaparkan deskripsi umum tentang pengelolaan Pendidikan Karakter di SMK Negeri 1 Stabat Kabupaten Langkat sebagai Pendidikan Karakter di Kabupaten Langkat. Penelitian ini memberikan gambaran dalam bidang pengelolaan pendidikan karakter pada aspek merencanakan, melaksanakan dan mengevaluasi serta mengidentifikasi berbagai faktor pendukung, faktor-faktor yang menjadi faktor penghambat atau kendala, beserta alternatif solusinya yang dilakukan di sekolah piloting pendidikan karakter yaitu di SMK Negeri 1 Stabat Kabupaten Langkat yang seterusnya dengan menyajikan bentuk deskripsi tentang pengelolaaan pendidikan karakter baik bidang perencanaan, pelaksanaan maupun evaluasi dengan berpedoman pada paradigma penelitian, yaitu diawali dengan pengelolaan perencanaan pendidikan karakter, pengelolaan pelaksanaan pendidikan karakter, dan evaluasi pendidikan karakter, pengidentifikasian berbagai faktor pendukung dan penghambat, serta pencarian solusi terhadap faktor penghambat.

\section{KESIMPULAN DAN SARAN}

\section{A. Kesimpulan}

1. Etika dan moral dalam pembelajaran yang sudah diuraikan di atas perlu dicermati dan diupayakan untuk bisa dipraktikkan dalam setiap proses pembelajaran, baik oleh pendidik (guru) maupun oleh peserta didik (siswa).

2. Pengembangan etika, moral, dan karakter di sekolah juga sangat penting untuk diperhatikan setiap guru, mengingat di sinilah peserta didik mulai berkenalan dengan berbagai bidang kajian keilmuan. Pada masa ini pula peserta didik mulai sadar akan jati dirinya sebagai manusia yang mulai beranjak dewasa dengan berbagai problem yang menyertainya.

3. Etika pendidikan merupakan sebuah proses pendidikan yang berlangsung secara etis dan terus-menerus dalam kehidupan seseorang melalui pengajaran dan penekanan terhadap etika itu sendiri.

\section{B. Saran}

1. Pendidikan moral akan berhasil apabila, guru memberi stimulus agar anak didik memberi respon sesuai dengan keinginan pendidik, dan dengan stimulus, respon itu anak didik diberi 
classical conditioning untuk menciptakan kondisi belajar yang lebih kondusif. Agar tujuan pendidikan moral dapat tercapai, guru dapat memberi prestasi kepada anak didik yang berhasil dan hukuman bagi yang gagal, namun dalam koridor memanusiakan manusia.

2. Dalam melaksanakan pendidikan bermoral untuk mewujudkan anak didik yang ideal, pendidikan harns mempu mengembangkan kapasitas peserta didik untuk membuat mereka sadar akan keberadaannya di dunia ini.

3. Arah kebijaksanaan pendidikan moral adalah untuk mewujudkan masyarakat sipil dengan parameter masyarakat lebih baik, demokratis, anti kekerasan, berbudi pekerti luhur, bermoral masyarakat mendapat porsi partisipasi lebih luas, serta adanya landasan kepastian hukum, mengedepankan nilai-nilai pancasila, nilai keadilan, menghargai HAM, penegakan hukum, menghargai perbedaan SARA dalam kesatuan bangsa.

\section{DAFTAR PUSTAKA}

Bertens, K, 2002, Etika, Jakarta: Gramedia Pustaka Utama. Cet. VII.

Bungin Burhan, 2010.Metodologi Penelitian Kualitatif, Jakarta: Raja Grafindo Persada.

Juhaya S. Praja, 2008, Aliran-Aliran Filsafat dan Etika, Jakarta: Prenada Media.

Marzuki. 2009, Prinsip Dasar Akhlak Mulia: Pengantar Studi Konsep-konsep Dasar Etika, Yogyakarta: Debut Wahana Press.

Miles dan Huberman, 2007, Analisis Data Kualitatif, Jakarta : Universitas Indonesia.
Parjono. 2005, Pendidikan Nilai-nilai Moral, Yogyakarta: MKV, UNY.

Surajiyo, 2005, Ilmu Filsafat Suatu Pengantari, Jakarta: Bumi Aksara.

Sugiyono, 2010, Metode Penelitian Pendidikan, Bandung: Alfabeta.

Sanjaya, Wina, 2007, Strategi Pembelajaran Berorientasi Standar Proses Pendidikan, Jakarta: Kencana. Cet. II.

Tilaar. H. A. R, 2009, Kekuasaan dan Pendidikan, Jakarta: Rineka Cipta.

Taniredja, Tukiran, 2013, Konsep Dasar Pendidikan, Yogyakarta: Ombak.

Wuri Wuryandani dan Fathurrohman. 2012, Pembelajaran Pendidikan Kewarganegaraan di Sekolah, Yogyakarta: Ombak. 